\title{
Anatomical and Radiological study on the skull of the Koala (Phascolarctos cinereus)
}

\section{A.S. Saber* and L.B. Fernando **}

${ }^{*}$ Faculty of Veterinary Medicine, University of Sadat City, Sadat City, Egypt \& Discipline of Anatomy and Pathology, School of Veterinary and Biomedical Sciences, James Cook University, Townsville, Australia

** Discipline of Clinical Sciences, School of Veterinary and Biomedical Sciences, James Cook University, Townsville, Australia.

\section{Abstract}

Four koala heads were used with the aim of studying the anatomy and radiology of the skulls. This study may establish baseline data necessary to help in understanding, interpreting $x$-ray images and treating some of the respiratory diseases or surgical affections of the head. In addition, it may pave the way for future functional and comparative anatomical and radiological studies.

The peculiarities of the skull were mentioned for both cranial and facial bones. The photos taken for the skull from all orientations (9 photos) as well as the two $x$-ray images were labeled using the recent nomenclature published by NAV (2005) and the illustrated veterinary anatomical nomenclature edited by Schaller (2007).

Keywords: Koala (Phascolarctos cinereus), Skull, Anatomy, Radiology, marsupials.

\section{Introduction}

The Koala (Phascolarctos cinereus) is a famous marsupial, which has eco-morphological and behavioral peculiarities such as sedentary, solitary, arboreal and tailless, having small brain and enormous gastrointestinal tract (proportionally, the largest of any mammal), is specialized for a diet of eucalyptus. It virtually able to go without drinking (the aborigines meaning of Koala is: I don't drink, Beatty, 1972), and possesses a zygodactyl grip (manual digits I and II oppose III-V) that it uses in hand-over-hand vertical climbing and clinging. Koalas, unlike most macropodes and diprotodontoids, which are lophodont, have selenodont molars. Koalas famously possess human-like fingerprints (Naish, 2011).

The need to know more about koala's functional anatomy is 
increasing with the increase in the number of the koalas in the koala's and wildlife sanctuaries in Australia (e.g. Lone Pine Koala sanctuary in Brisbane, Hanson Bay Wildlife Sanctuary in Kangaroo Island, Kuranda Koala Gardens in Kuranda and Koala gardens in Sydney) and allover the world e.g. San Diego Zoo in USA.

Recently, sporadic scientific works were published on the anatomy and development of the koala by Grand and Barboza (2001), the orbital anatomy of the koala by Kempster and Hirst, (2002), the cranial anatomy of a koala fossil compared by the extant koala by Louys et al., (2009) and the paranasal sinuses of the koala by Hemsley et al., (2013) using the CT and MRI. Radiological studies on the koala's head could not be found and still missing in the available literatures.

The aim of this work is to use the skull anatomy of koala, without fine details, to establish baseline data necessary to help in understanding, interpreting the $x$-ray images and treating some of the diseases or affections of the head as well as paves the way to future functional and comparative anatomical and radiological studies

\section{Material and Methods}

J. Vet. Anat.
Four skulls of koalas were used in the study. One skull was kept in the anatomy museum and three heads were found frozen in the Discipline of Anatomy and Pathology, School of Veterinary and Biological Sciences, James Cook University, Townsville, Australia. Neither the sex nor the age of these specimens could be identified. Two heads were $x$-rayed in the latero/medial and dorso/ ventral positions using the parameters $\mathrm{kV} 53$ and $5 \mathrm{mAs}$. The three heads, then after, were boiled and cleaned and used for the anatomical study. The skulls were photographed in the lateral, dorsal, rostral, caudal and sagittal views using a Samsung Digital Camera (WB700). The nomenclatures of the NAV (2005) as well as the illustrated veterinary anatomical nomenclature edited by Schaller (2007) were used together with the old ones used in the relevant literatures (in brackets).

\section{Results and discussion}

Nine photos for the koala's skull in different views (dorsal, lateral, rostral, caudal and sagittal) (figs 1-9) were used to support and help in reading the radiographs. Labeling of the koala's head $x$-ray images (latero/ medial \& dorso/ ventral) are shown in figs $(10,11)$.

Based upon the habitual posture of the koala, its head postured upon 
the neck to a degree of forward flexion (Grand and Barboza, 2001). The skull as a whole was rectangular in shape and had nearly the same width. It was formed of facial and cranial components.

\section{Facial component}

The bones of the face were the Maxilla, incisive (premaxilla), Palatine, Pterygoid, Nasal, Lacrimal, Zygomatic (Jugal), Dorsal turbinate, Ventral turbinate, Vomer, Mandible and Hyoid.

The most peculiar anatomical features of the koala's head could be listed in the following:

- The face was longer than the cranium (figs 1,2). The cranio-facial index (the relation of the distance from the occipital crest to the fronto-nasal suture to that between the latter and the nasal notch) was 9:3.8 in Koala. This ratio varies from $10: 3$ in extreme brachycephalic breeds of dogs to 10:7 in extreme dolichocephalic subjects (Sisson, 1910).

- In profile the frontal and nasal bones were nearly on the same line (fig 1,2).
- A nasolacrimal fossa and canal caudal to the orbital margin, as seen in human and domesticated animals such as cat and dog, was not present in Koala.

- The bodies of the incisive bone (premaxilla) of both sides were not fused rostrally (fig 6,9 ).

- The orbits were directed rather rostrally than laterally like in most herbivores. It may had evolved this character from a need to mobilize skillfully and safely around its arboreal environment (Kempster et al., 2002). The same authors mentioned that the orbit lacks a bony roof and is bridged by fibrous band, the orbital ligament. This ligament extends between the supraorbital process of the frontal bone and the frontal process of the zygomatic bone.

- Eight bones formed the bony orbit: the Frontal, Lacrimal, Zygomatic (Jugal), Maxillary, Palatine, Temporal (Squamosal), and Sphenoid (basisphenoid and alisphenoid) (Kempster et al., 2002). They mentioned that the orbital rim was formed superomedially by the frontal bone and its supraorbital 
process, rostroinferiorly by the lacrimal bone, and inferiorly, extending out laterally, by the zygomatic bone and its frontal process.

- The lacrimal bone contained two quite well-defined bony canaliculi which opened on the rostral surface of the lacrimal bone and orbital margin (fig 2). This manner is similar to that in other marsupials (Dixon, 1989).

- Three paranasal sinuses were identified in the Koala's head, namely: maxillary (which is divided into rostral maxillary recess with its ventral conchal sinus, and caudal maxillary sinus), a frontal and a small sphenoid (not identified in the $x$-ray image) (fig 1, 10/1, 2, 2', 2"). Kratzing (1984) referred to two separate maxillary sinuses communicating with the nasal cavity ventral to the ventral nasal concha and a ventrocaudal maxillary sinus communicating widely with the ventral nasal meatus near the chaenae. Hemsley et al. (2013), in koala also, termed the rostral maxillary sinus described by Kratzing (1984) as maxillary recess and said that the caudal maxillary sinus which he identified is consistant with the "maxillary sinus" or " ventrocaudal maxillary sinus" referred by Krazing (1984) and Negus (1958).

Two frontal sinuses, one of which was continuous with the rostral maxillary sinus, were claimed to be present in koala by Kratzing (1984). Hemsley et al. (2013) described only single frontal sinus and said that the more rostral of the frontal sinuses described previously actually corresponds to the ventral conchal sinus.

- The nasal septum divided the nasal cavity into two halves, right and left (fig 6). It is cartilaginous in the rostral third and osseous in the caudal two-thirds of the cavity (Hemsley et al., 2013). In the rostral part of the nasal cavity Kratzing (1984) mentioned that the base of the septum extended to accommodate the vomeronasal organ and an extensive glandular area.

- The nasal cavity was occupied by dorsal and ventral conchae as well as the ethmoturbinate at its 
most caudal part. The dorsal concha was a thin plate projecting ventrally from the nasal bone, parallel to the nasal septum. The ventral concha consisted of a larger curved osseous scroll and occupied mush of the rostral nasal cavity (figs 1, 6). These findings agreed with that mentioned by Kratzing (1984) and Hemsley et al. (2013) in the same animal. The former author described the ethmoidal region as consisted of four endoturbinate bones with a smaller ectoturbinate bone on each side of the perpendicular plate. He added that the lack of complex scrolling of the dorsal and ventral conchae is in contrast with the anatomy of most mammals. This may therefore lead to a prediction that cryptococcosis in koalas would similarly primarily affect the lungs, however, this is not invariably the case, with the nasal cavity being the primary site of infection in many instances (Krockenberger et al., 2002).

- The mandible presented a deep masseteric fossa flanked rostrally and caudally by muscular crests. Its angular process was pointed and directed dorsally (Fig 7). The mandibular symphysis was completely fused. This fusion allows the transfer of forces generated by balancing side muscles to the working side of the jaw (Compton and Lieberman, 2005)

- The dental formula of Koala was I $3 / 1$ C $1 / 0$ Pm 1/1 M 4/4 (Hyett and Shaw, 1980). Koala had selenodont molars i.e. the cusps are lunate when seen in occlusal view, with the concave side of the curve facing outwards (Naish, 2011), (Fig.8). An additional lower molar had been found in one specimen only as described by Beddard (1958).

- The mandible was narrower than the maxillary jaw resulting in maxillary teeth, which protruded beyond the level of the mandibular ones (fig 9). This arrangement may give better chance for the lateral movement of the jaw and the shearing action done by the saw-like teeth occlusion surfaces.

- Louys et al., (2009) commented, that the dramatic changes in the cranial morphology of the koala 
(Phascolarctos), especially in the facial region, is therefore probably related to demand of increased transversely oriented masticatory loading of the cheek teeth, in response to a change to a tougher diet of eucalyptus leaves.

\section{Cranial component}

- The bones of the cranium were the Occipital, Sphenoid, Ethmoid, Interparietal, parietal, Frontal and Temporal (Squamosal). The first four were single, the others paired.

- The neurocranium approached a rectangular (fig 1) Louys et al., (2009).

- The cranial cavity was relatively small (fig 1,10). The brain is about $2 \%$ of body mass in humans, while it is about $0.2 \%$ in koalas. Flannery (1995) mention-ed that the brain hemispheres sit like shriveled halves on the top of the brain stem. In contact neither with each other nor the bones of the skull. It is the only mammal on earth with such a strangely reduced brain. In humans, the difference between the size of the inner cranium and the size of the brain is $20 \%$. In koalas, about $40 \%$ of the cranium is filled with cerebrospinal fluid. Moreover, the same reference added that the koala's brain surface is smooth and portions of the brain associated with motor movement show than even greater reduction others ${ }^{1}$.

- Koala had inter-parietal bone which extended more rostrally and caudally as well. Louys et al., (2009) said that the interparietal protrudes slightly caudally creating a convex caudal margin of the skull when viewed dorsally. It is found also in other domestic animals as horse, sheep, goat, large ruminants, pig (Popesko, 1977).

- The external sagittal crest was less prominent and splits at the caudal fourth of the parietal bones into two divergent parts lateralward, inclosing the interparietal bone in between.

- Louys et al., (2009) mentioned that koala's basioccipital is slightly larger than the basisphenoid.

- The palate (fig 1,10 ) was slightly arched, rostrodorsally, forward of the first 
molar (in agreement with Louys et al., (2009).

- There were two large palatine foramina (fig 3) which were non-homologous structures as described by Voss and Jansa (2003) whom called them palatine vacuities

- The ventral margin of the zygomatic process was formed entirely by the maxilla.

- The superficial masseter process was formed entirely by the maxilla (fig 2).

- The glenoid fossa was rectangular and slightly parallel to the postglenoid process (Louys et al., (2009).

- Koala showed significant ventral inflation expansion of the osseous auditory bulla which was part of the middle ear (figs 1,2,4,5, 10,11). The same findings were recorded by Louys et al., (2009). In addition, they postulated that the large middle ear volume is associated with the increased sensitivity to low frequency sound. It is known that koala produces loud "bellows", typically in context of mating or agonistic behavior (Smith, 1987; Mitchell, 1991). The later authors added that koala bellows are low pitched, and approach the optimum for long distance sound propagation. This modification in the hearing apparatus of the koala provides the animals with larger spatial capacity both for social communications and for detection of predators (Fleischer, 1978; Webster, 1962, 1966).

\section{Acknowledgment}

We want to express our cordial thanks to Mrs. Kerry Johns, the Anatomy technician in the Discipline of Anatomy and Pathology, School of Veterinary and Biomedical Sciences, JCU for preparing the koalas skulls used in this study.

\section{References}

Beatty, B. (1972): Unique to Australia. URE Smith Pty Ltd. Sydney.

Beddard, F. (1958): Mammalia, Vol. X. a reprint edition from 1902, by Macmillan \& Co., Limited

Compton, A.W. and Lieberman, D. (2005): Biomechanics of the fused mandibular symphysis in placental and marsupial herbivores. American Journal of Physical Anthropology, S 40: 89-90. 
Dixon, J.M. (1989): Thylacinidae, In: Walton DW, Richardson BJ, editors. Fauna of Australia. Vol. IB, Mammalia. Canberra: Australian Government Publishing Services. $p$ 552

Flannery, T. (1995): The future eaters: an ecological history of the Australian lands and people. New York: G. Braziller.

Fleischer, G. (1978): Evolutionary principles of the mammalian middle ear. Advances in Anatomy, Embryology and Cell Biology 55: 170.

Hemsley S, Palmer H, Canfield R, (2013): Computed tomographic anatomy of the nasal cavity, paranasal sinuses and tympanic cavity of the koala. Aust Vet J. Sep; 91(9): 353-65.

Hyett, J. and Shaw, N. (1980): Australian Mammals. A field guide for New South Wales, Victoria, South Australia \& Tasmania. Tomas Nelson Australia.

Kempster, R.C., Bancroft, B.J. \& Hirst, L.W. (2002): Intraorbital anatomy of the koala (Phascolarctos cinereus). Anatomical Record. 267(4), 277287.
Kempster, R.C. and Hirst, L.W. (2002): Bony Orbital Anatomy of the Koala (Phascolarctos cinereus). The Anaomical record, 267: 288-291

Kratzing, J.E. (1984): The anatomy and histology of the nasal cavity of the koala (Phascolarctos cinereus). J. Anat. 138, 1: 55-65.

Krockenberger, M.B.; Canfield, P.J. and Malik, R. (2002): Cryptococcus neoformans in the koala (Phascolarctos cinereus) colonization by $\mathrm{C}$. $\mathrm{n}$. var gattli and investigation of environmental sources. Med Mycol, 40: 263-272.

Mitchell, P.J. (1991): Social behavior and communication of Koala: pp.151-170 in A.K.Lee, K. Handasyde, and G.D.Sanson (eds.). The Biology of the koala. Surrey Beatty and Sons, Sydney, Australia.

Naish, D (2011): Of koalas and marsupial lions: the vombatiform radiation, part I, Tetrapod Zoology Home, October 26.

http://blogs.scientificamerican.com/t etrapod-

zoology/2011/10/26/vombatiformradiation-part-i/

Negus, V. (1958): The comparative anatomy and physiology of the nose and paranasal sinuses. E\&S Lovingstone, Edingurgh, 303-304, 294-296 
Nomina Anatomica Veterinaria (2012): NAV, $5^{\text {th }}$ ed (revised). Prepared by International Committee on Veterinary Gross Anatomical Nomenclature (ICVGAN). Authorized by the General assembly of the World Association of Veterinary Anatomists (WAVA), Knoxville. TN (USA) 2003.

Popesko, P (1977): Atlas of topographic anatomy of the domestic animals. W.B. Saunders Company, Philadelphia, London, Toronto.

Schaller, O. (editor) (2007): Illustrated veterinary anatomical nomenclature, $2^{\text {nd }}$ ed. Enke Verlag, Sttgart, 14: 178-179

Sisson, S. (1910): A text book of veterinary anatomy. W.B. Saunders Company,

Smith, M. (1987): Behaviour and ecology; pp. 56-78 in L.Cronin (ed.). Koala: Australia's Endearing Marsupial. Reed Books, Sydney.

Stewart M, Krockenberger $M$, Malik R. (2013): Computed tomographic anatomy of the nasal cavity, paranasal sinuses and tympanic cavity of the koala. Aust Vet J.; 91(9): 353-65

Voss, R.S. and Jansa, S.A. (2003): Phylogenetic studies on didelphid marsupials II. Nonmolecular data and new IRBP sequences: separate and combined analyses of didlephin relationships with denser taxon sampling. Bulletins of the American Museume of Natural History 276: 182.

Webster, D.B. (1962): A function of the enlarged middle-ear cavities of the kangaroo rat, Dipodomys. Physiological Zoology 35: 248-255.

Webster, D.B. (1966): Ear structure and function in modern mammals. American Zoologist 6: 451-466.

\section{Internet sites:}

1) http://terriblepunyrightness.w ordpress.com/2011/02/02/th e-functional-anatomy-ofsitting-part-1/ (retrieved 22/11/201

Correspondence address:

E-mail: saberasraf 2@yahoo.com 


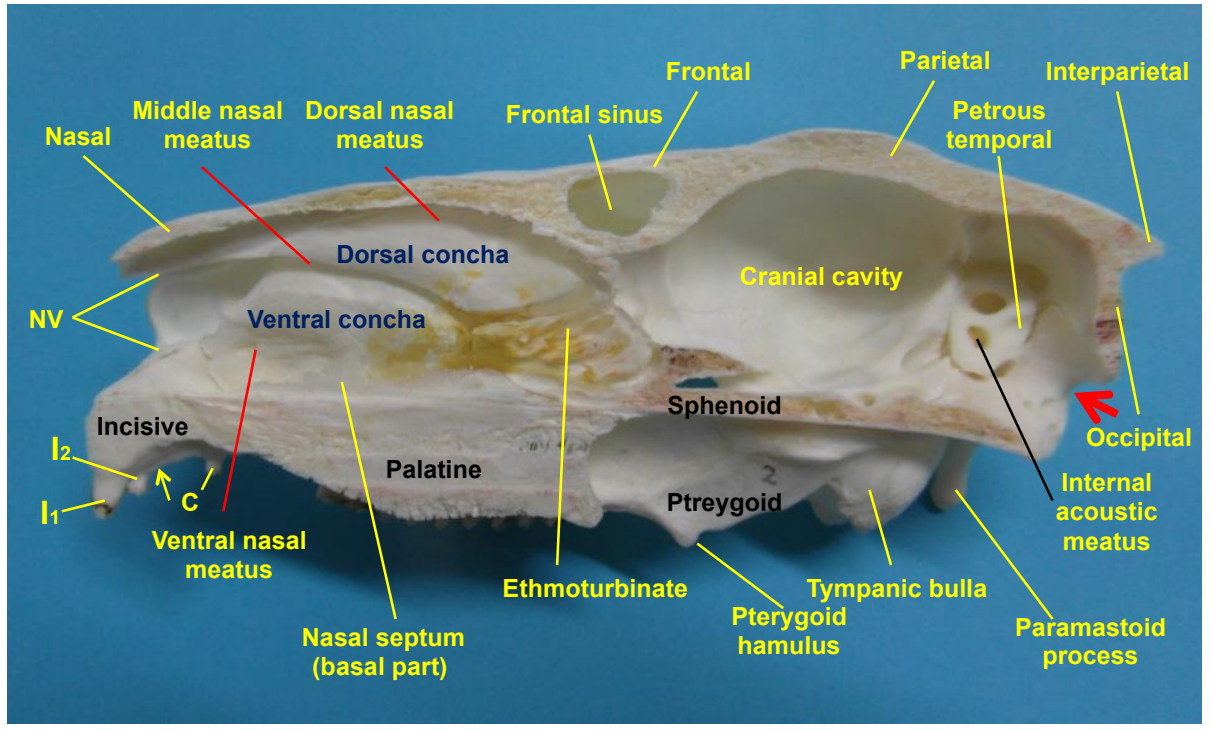

Fig (1): Koala skull, sagittal view

$\mathrm{I}_{1-3}$ Upper incisors, C Canine, NV entrance of the nasal vestibule,

Yellow arrow indicates the $\mathrm{I}_{3}$ place (missing), Red arrow indicates the foramen magnum

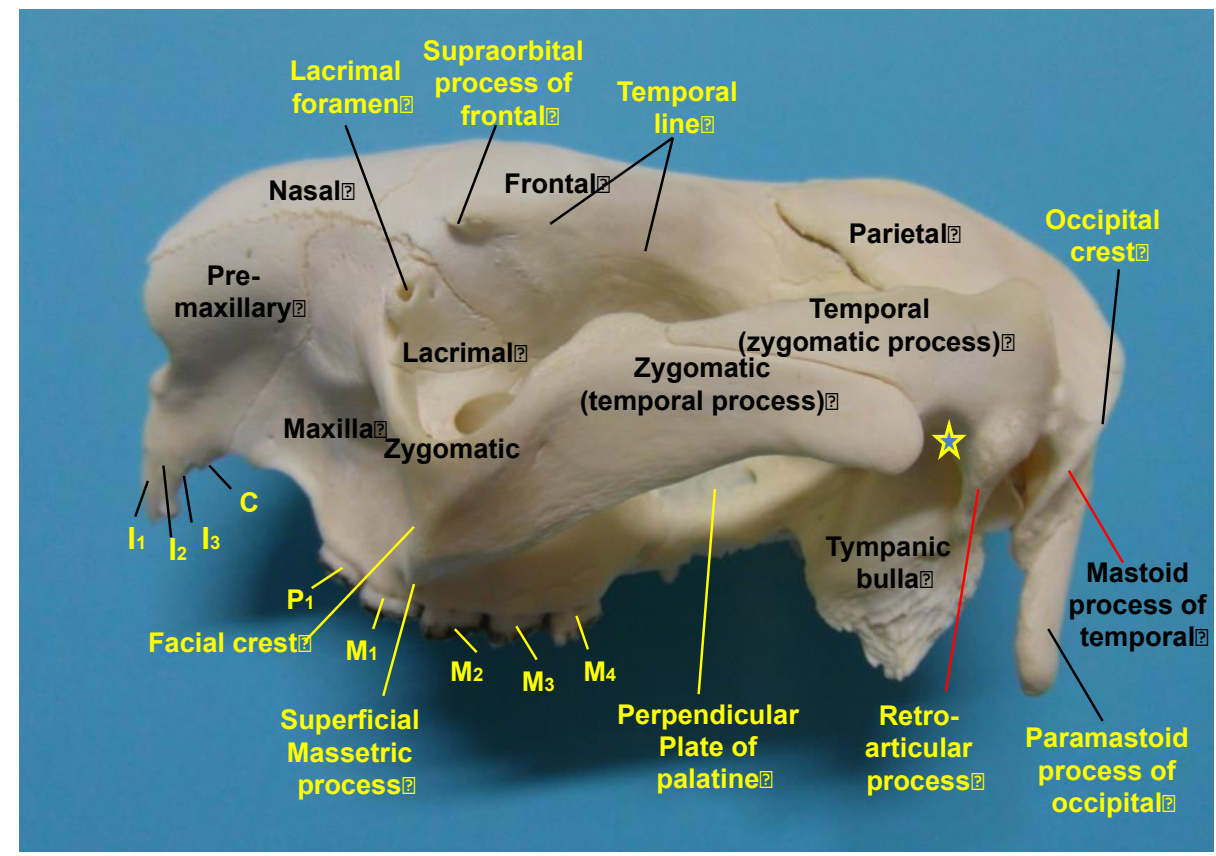

Fig (2): Koala skull, lateral view

$\mathrm{I}_{1-3}$ Upper incisors, $\mathrm{C}$ Canine, $\mathrm{P}_{\mathrm{I}}$ premolar, $\mathrm{M}_{1-4}$ molars (Star indicates the site of the TMJ)

J. Vet. Anat. 


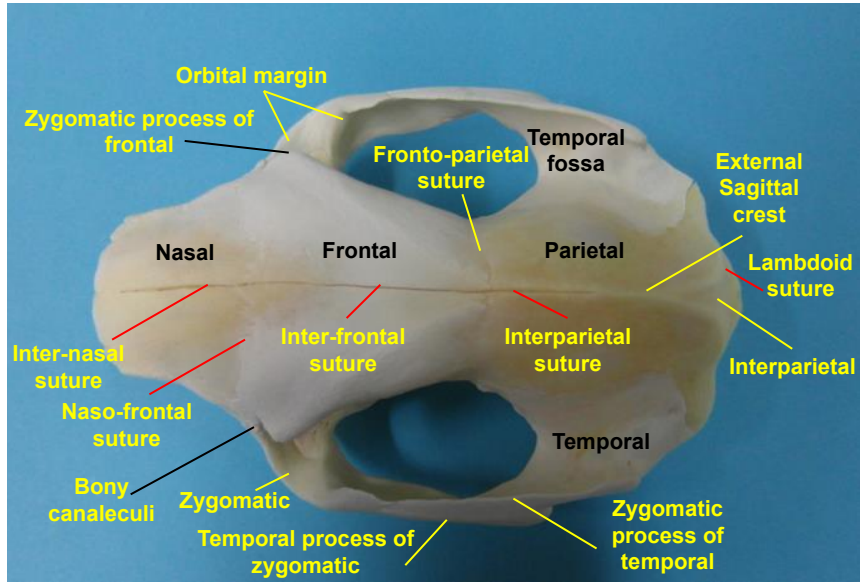

Fig (3): Koala skull, dorsal view, showing the cranial and facial bones and the sutures in between.

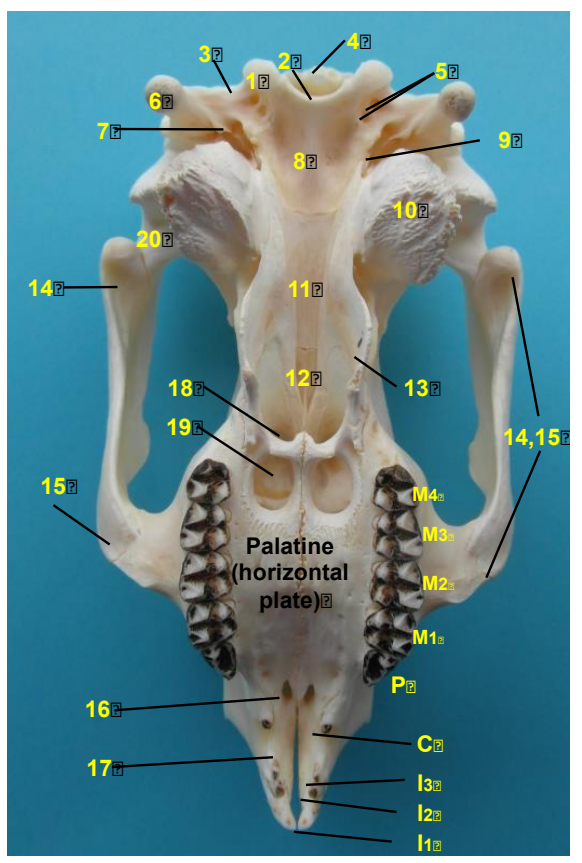

Fig (4): Koala skull, ventral view showing: 1 Occipital condyle, 2 Foramen magnum, 3 Ventral condylar fossa, 4 External occipital protuberance, 5 Hypoglenid foramina, 6 Paracondylar process, 7 Jugular foramen, 8 basilar part of occipital, 9 External acoustic meatus, 10 Tympanic bulla, 11 Body of basisphenoid bone, 12 Body of presphenoid bone, 13 Perpendicular plate of palatine bone, 14, 15 Zygomatic arch, 14 Zygomatic process of squamosal (temporal bone). 15 Temporal process of jugal (zygomatic), 16 Palatine fissure, 17 Body of incisive bone, 18 Choancae, 19 Palatine vacuaity. 20 Glenoid fossa. 


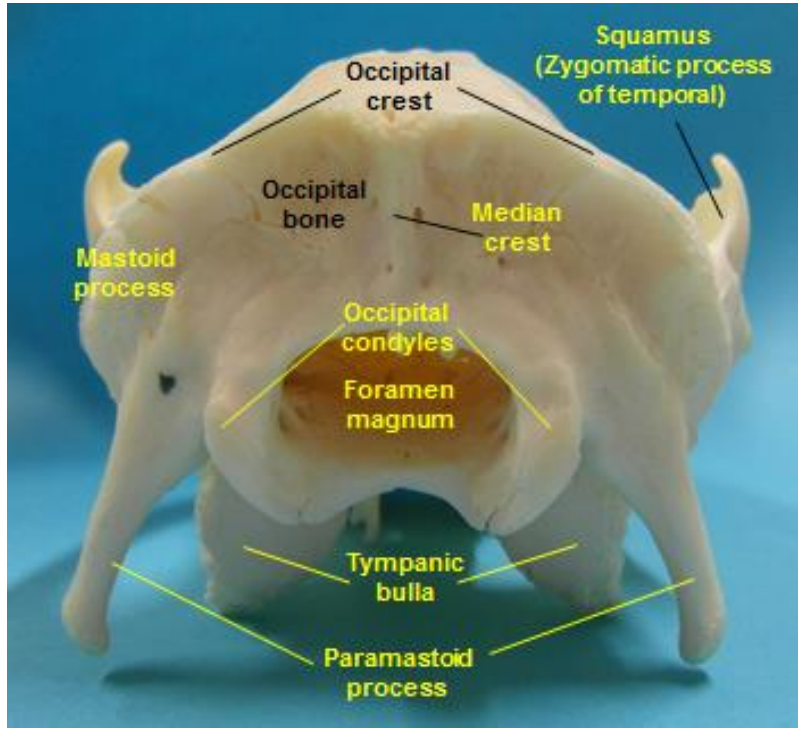

Fig (5): Koala skull, caudal (occipital) view.

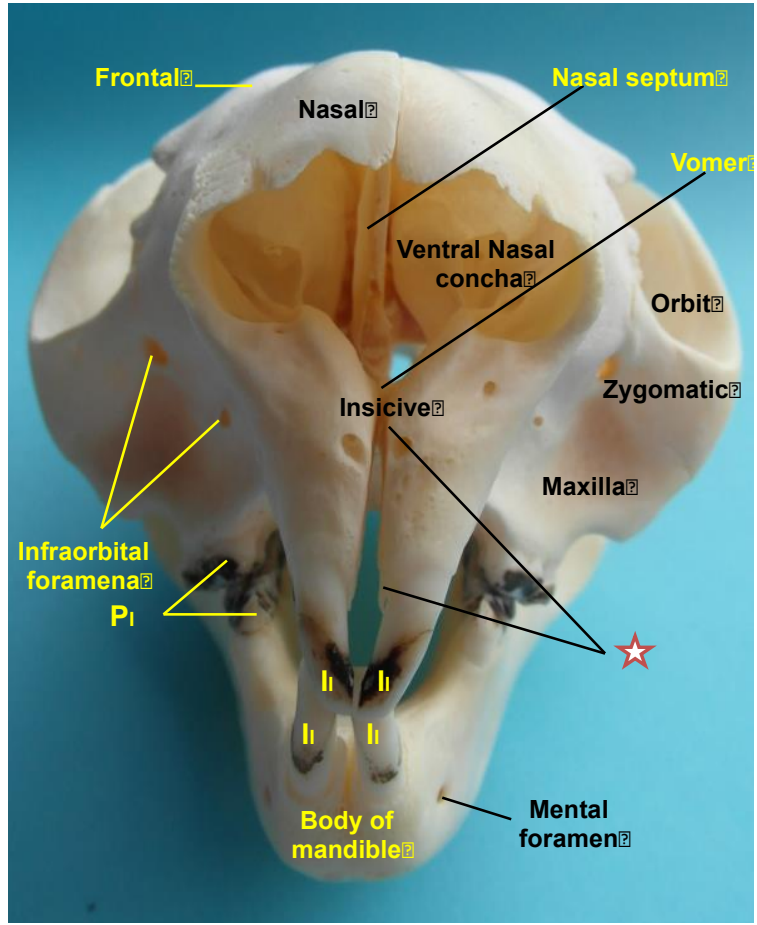

Fig (6): Koala skull, rostral view. Notice: the unfused premaxillas (incisive bones) and the double infraorbital foramin. 


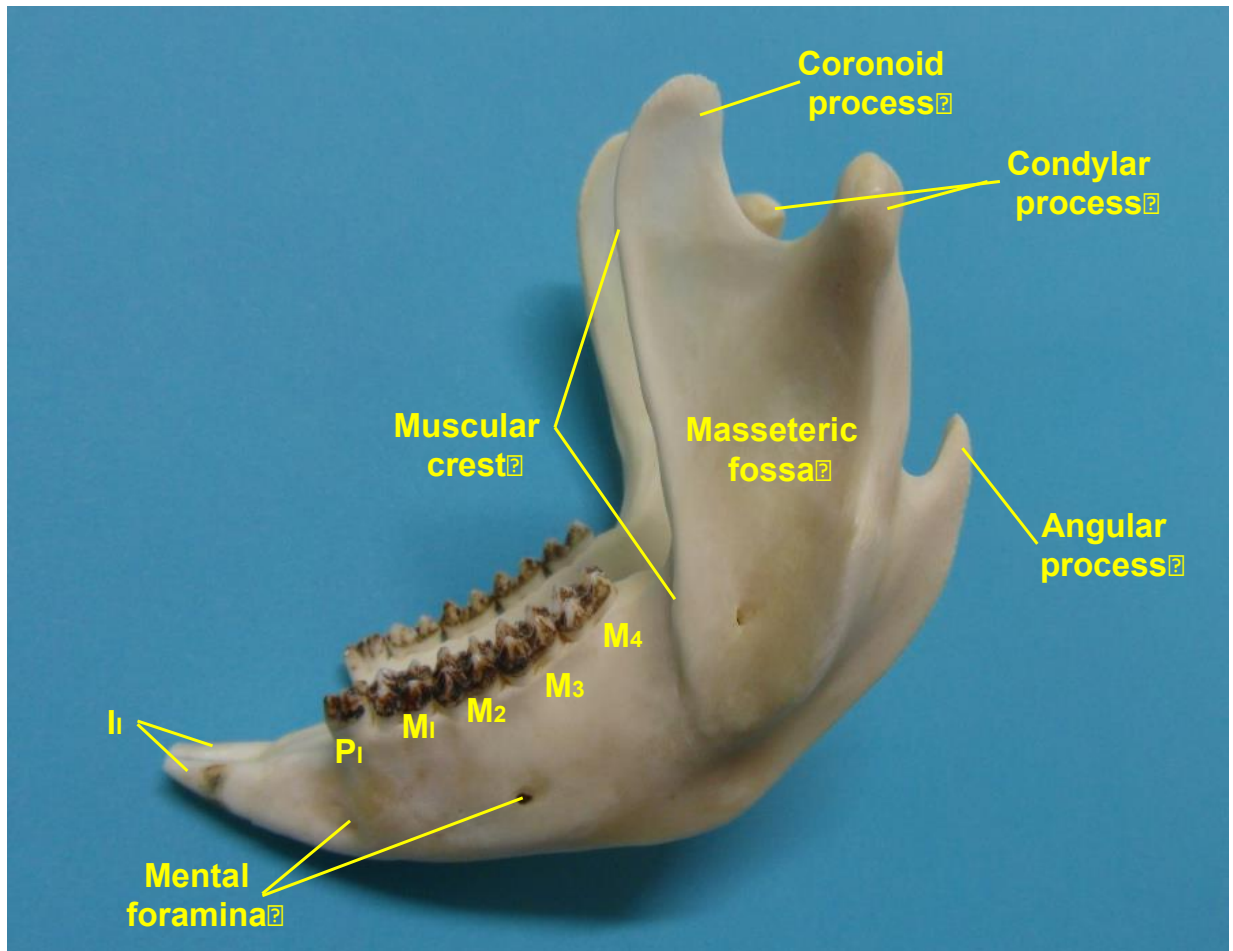

Fig (7): Koala mandible, lateral view. Notice the deep masseteric fossa, the prominent muscular crest, the double mental foramina and the two mandibular incisors (diprotodonty).

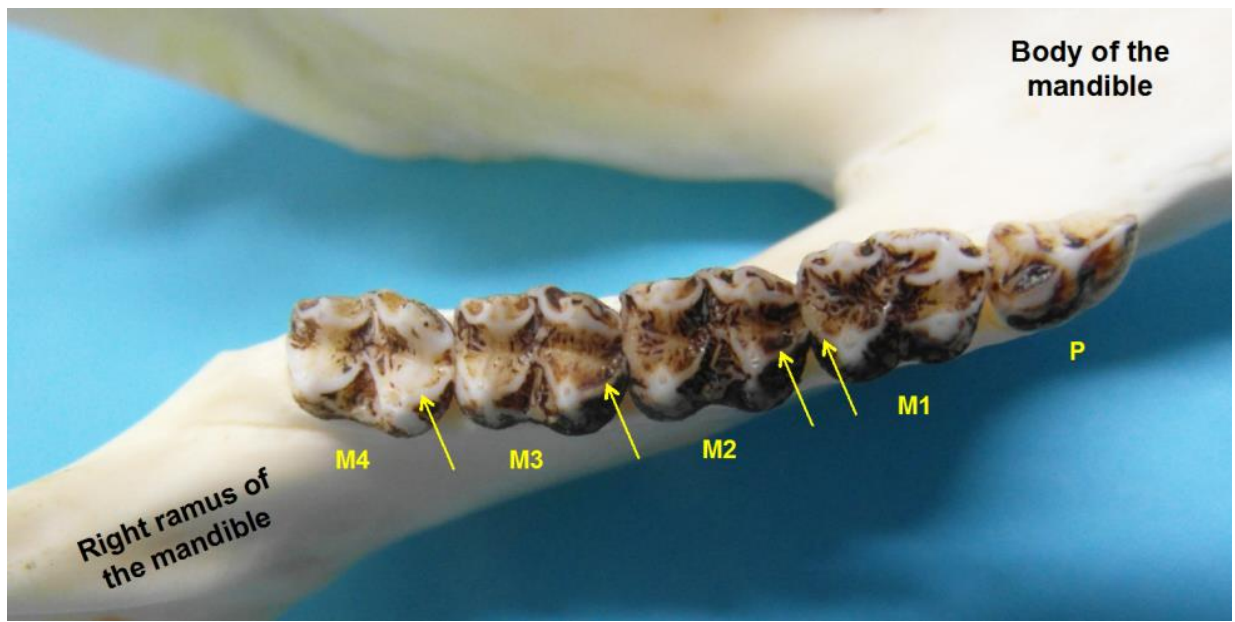

Fig (8): Koala mandibular teeth, dorsal (occlusal) view. Notice the selenodont type of molars (the cusps are lunate with the concave side of the curve facing outwards, arrows). 


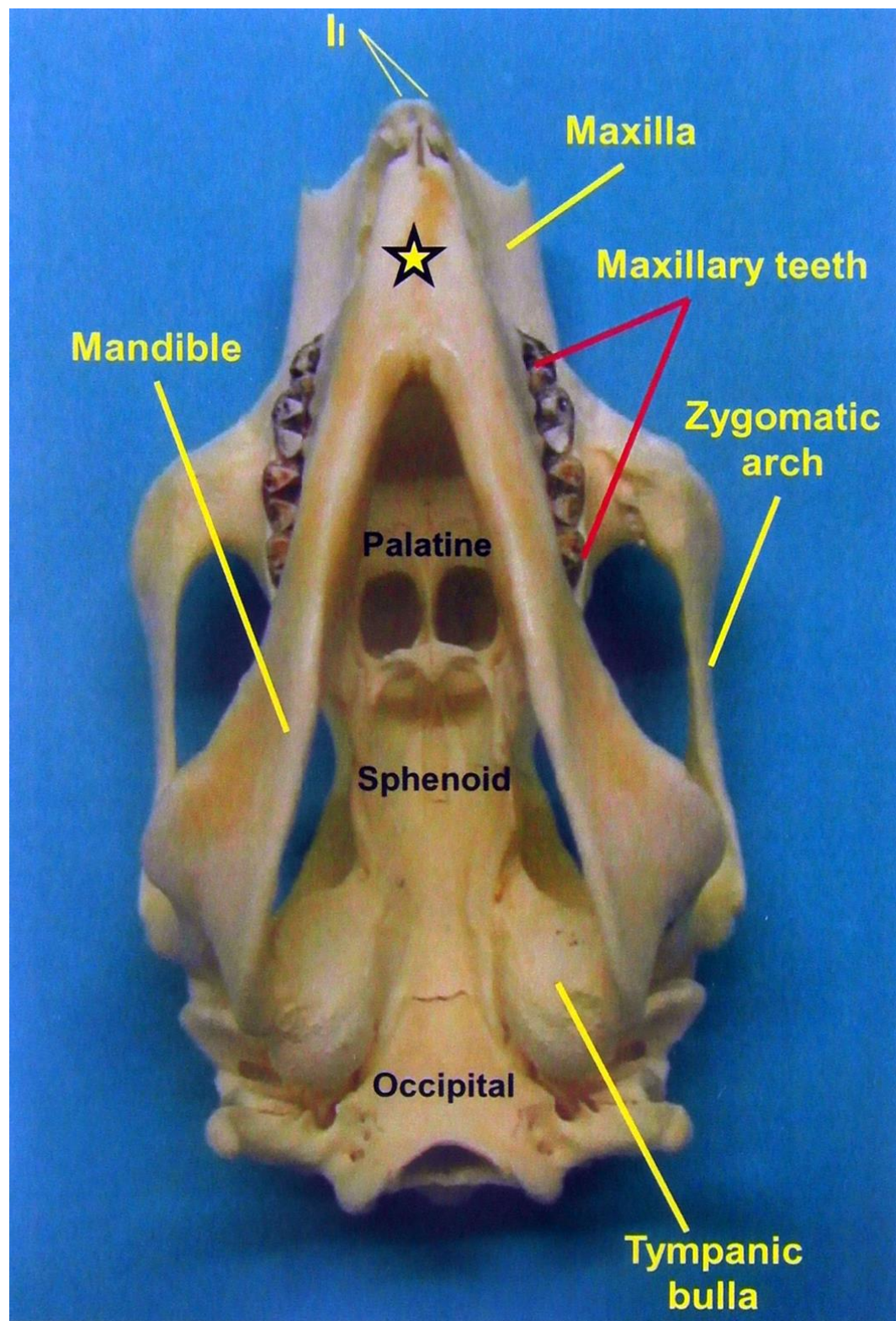

Fig (9): Koala skull with mandible, ventral view.

Notice that the narrow mandible and the protrusion of the maxillary cheek teeth beyond mandibular one. Notice also the complete fusion of the mandibular symphysis (star). 


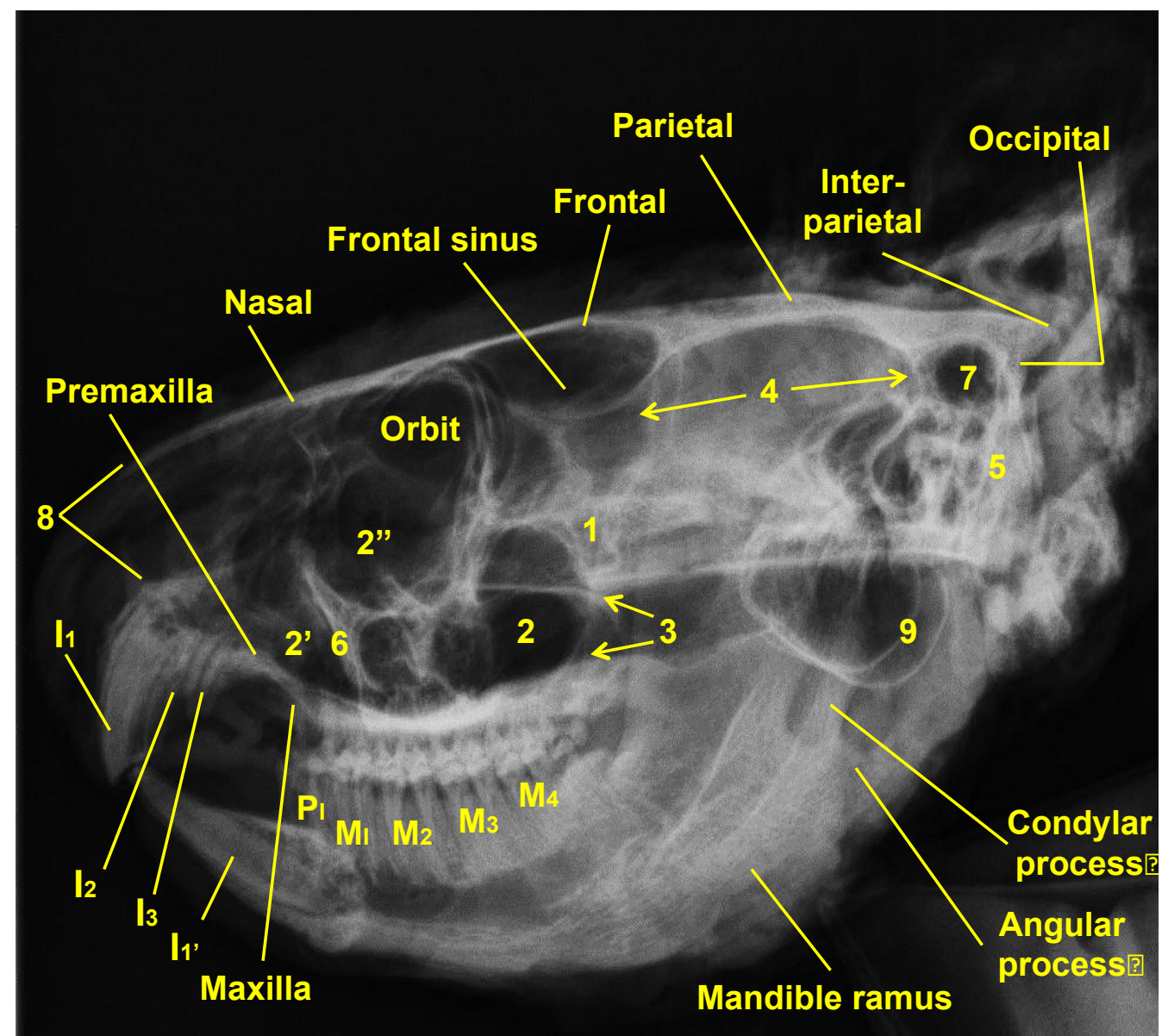

Fig (10): X-ray image of the head of Koala, Lateral view showing:

1 Jugal (zygomatic bone, 2 Maxillary sinus, 2' Maxillary sinus (rostral part), 2" Its conchal sinus, 3 Sphenoid sinus, 4 Cranial cavity, 5 Tympanic bulla, 6 Facial crest, 7 External auditory meatus, 8 Nasal vestibule, 9 Tympanic bulla

$\mathrm{I}_{1-3}$ Upper incisors $\mathrm{I}_{1}$ Lower incisor, $\mathrm{P}_{1}$ Premolar, $\mathrm{M}_{1-4}$ Molars. 


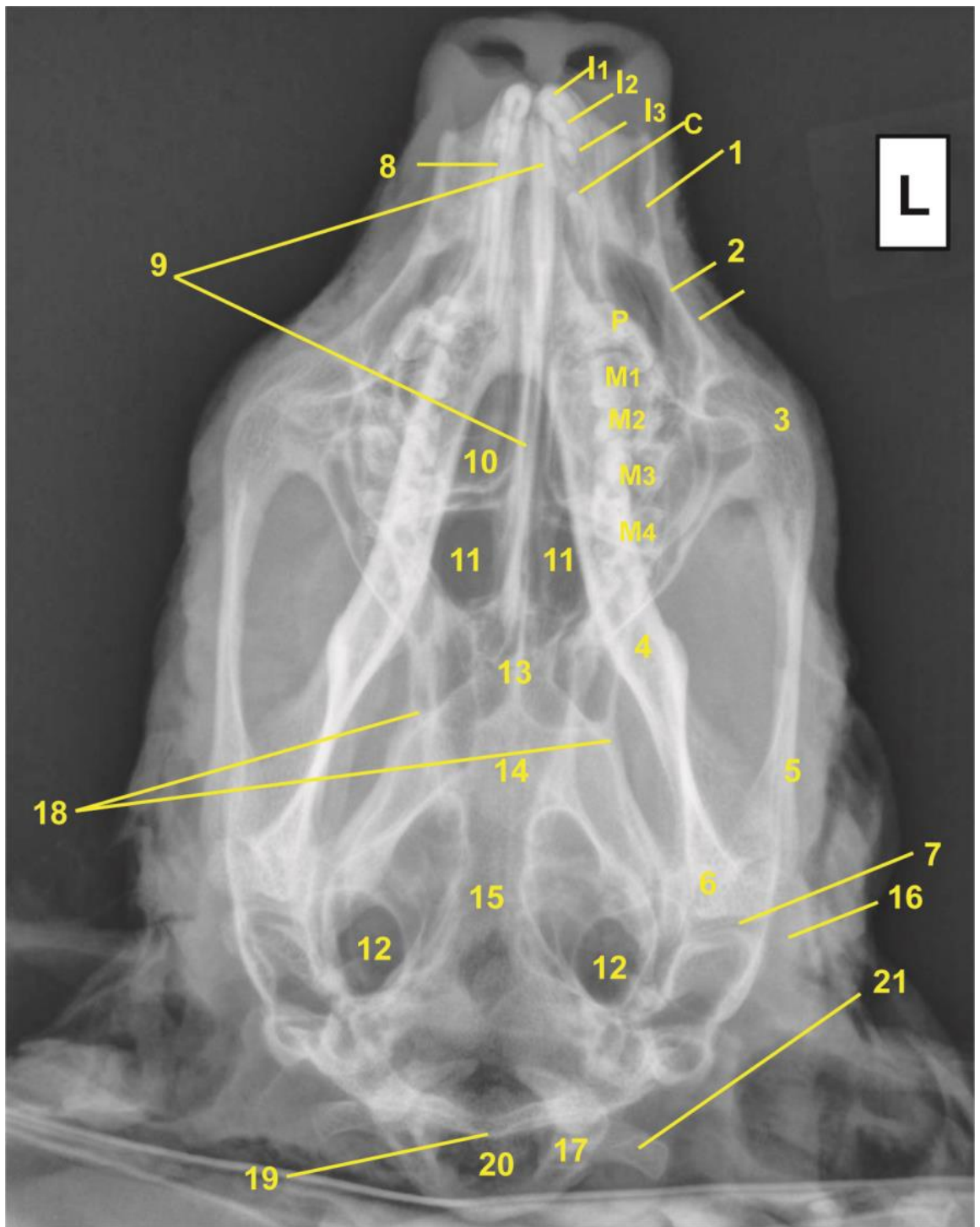

Fig (11): X-ray image of the head of Koala, ventro/dorsal view showing:

$\mathrm{I}_{1-3}$ Upper incisors, $\mathrm{C}$ canine, $\mathrm{P}$ premolar, $\mathrm{M}_{1-4}$ molars, 1 Nasal bone, 2 Maxilla, 3 Zygomatic bone (jugal), 4 Ramus of the mandible, 5 Zygomatic process of temporal bone (squamosal), 6 Condylar process of the mandible, 7 Temporomandibular joint, 8 Incisive bone, 9 Vomer bone, 10 Choana, 11 Palatine vacuaities, 12 Tympanic bullae, 13 Palatine bone, 14 Basisphenoid, 15 Basioccipitalis, 16 Retroarticular process, 17 Occipital condyle, 18 Cranial cavity, 19 Parietal bone, 20 Foramen magnum, 21 Paramastoid process. 